BULLETIN Bulletin hispanique

HISPANIQUE Université Michel de Montaigne Bordeaux

$120-2$ | 2018

Varia

\title{
Anticlericales y reaccionarios: un episodio poco conocido de Menéndez Pelayo en Vida Nueva (1898-1900)
}

Anticléricaux et réactionnaires. Menéndez Pelayo et Vida Nueva (1898-1900) : un épisode méconnu

Anticlerics and reactionaries. Menéndez Pelayo and the "Vida Nueva" (1898-1900): a little-known episode

José Bernardo San Juan

\section{OpenEdition}

\section{Journals}

Edición electrónica

URL: https://journals.openedition.org/bulletinhispanique/7175

DOI: 10.4000/bulletinhispanique.7175

ISSN: 1775-3821

Editor

Presses universitaires de Bordeaux

Edición impresa

Fecha de publicación: 10 diciembre 2018

Paginación: 627-642

ISBN: 979-10-300-0337-6

ISSN: 0007-4640

\section{Referencia electrónica}

José Bernardo San Juan, «Anticlericales y reaccionarios: un episodio poco conocido de Menéndez Pelayo en Vida Nueva (1898-1900)», Bulletin hispanique [En línea], 120-2 | 2018, Publicado el 02 enero 2022, consultado el 08 enero 2022. URL: http://journals.openedition.org/bulletinhispanique/7175 ; DOl: https://doi.org/10.4000/bulletinhispanique.7175 


\title{
Anticlericales y reaccionarios: un episodio poco conocido de Menéndez Pelayo en Vida Nueva (1898-1900)
}

\author{
JosÉ BERNARdo SAN JUAN \\ Universidad rey juan carlos
}

Anticléricaux et réactionnaires. Menéndez Pelayo et Vida Nueva (1898-1900) : un épisode méconnu.

Les contenus des revues littéraires permettent de compléter le panorama culturel du XIX siècle. Cet article met en lumière l'orientation anticléricale de la revue Vida Nueva (1898-1900), peu étudiée jusqu’à présent, ainsi que le conflit qui, en raison de son anticléricalisme, l'a opposée à Marcelino Menéndez Pelayo.

Mots-clés: Marcelino Menéndez Pelayo, Anticléricalisme, Vida Nueva (1898-1900).

Los contenidos literarios de las revistas permiten completar el retrato cultural del siglo XIX espańol. La cabecera Vida Nueva (1898-1900) ha permanecido prácticamente inexplorada hasta nuestros días. En este artículo se analiza cómo fue el anticlericalismo de esta publicación y se da a conocer el conflicto que, a causa de ese anticlericalismo, tuvo con Menéndez Pelayo.

Palabras clave: Marcelino Menéndez Pelayo, Anticlericalismo, Vida Nueva (18981900).

Anticlerics and reactionaries. Menéndez Pelayo and the "Vida Nueva" (1898-1900): a little-known episode

The content of the literary magazines allow us to complete the cultural portrait of the nineteenth century. "Vida Nueva" (1898-1900) has not been studied until now. This article discusses the anti-clericalism of this publication, and discloses the conflict that took place with Marcelino Menéndez Pelayo on those grounds.

Keywords: Marcelino Menendez Pelayo, Anti-clericalism, Vida Nueva (1898-1900). 


\section{INTRODUCCIÓN}

En los últimos años se ha producido una revisión del retrato cultural del siglo XIX español como resultado del estudio de los contenidos literarios de la prensa. Esta nueva mirada se fundamenta en la convicción de que las publicaciones periódicas permitirían ofrecer una imagen más rica de la sociedad en la que se habían impreso. Y sería posible a través del análisis de qué clase de textos contenían y en qué medida interesaban, de qué autores importaban y de con qué criterios eran juzgados. Todas estas informaciones, contrastadas unas con otras y puestas en contexto, son las que han permitido comprender mejor, por ejemplo, la complejidad del fin de siglo, un periodo que en no pocas ocasiones se había entendido en exclusiva de acuerdo con categorías estancas como modernismo o generación del 98. Ya Ortega atribuía a las revistas literarias una "misión placentaria» ${ }^{1}$ en la medida en que en ellas se incubaban aquellas tendencias que luego se asentarían -pero también aquellas que no llegarían a triunfar.

Dentro de esa revisión la cabecera Vida Nueva (1898-1900) ha sido -a causa del difícil acceso a sus ejemplares- la más desconocida. Y sin embargo se trata de una revista nuclear para comprender los movimientos de fondo de su época: «tan excelente cuanto olvidado semanario» ${ }^{2}$ diría en 1927 uno de sus colaboradores. Sólo recientemente se han estudiado sus páginas por medio de trabajos que abordan tanto cuestiones hemerográficas ${ }^{3}$ como aspectos relacionados con algunos de sus colaboradores: Azorín ${ }^{4}$, Rubén Darío ${ }^{5}$, Ganivet $^{6}$ y Juan Ramón Jiménez ${ }^{7}$. Pero aún no se ha tratado cómo fue su relación con Menéndez Pelayo, una relación que estuvo marcada por la tensión entre una revista anticlerical y un autor católico.

El análisis de los encuentros y desencuentros entre ambos ofrece interés por varias razones. Por un lado permite comprender cómo y en qué forma fue anticlerical una de las publicaciones con mayor número de intelectuales de la época. Esta labor aún no se ha realizado y es urgente por cuanto no es posible entender adecuadamente la historia cultural del siglo XIX sin contemplar las

1. José Ortega y Gasset, «Sobre un periódico de las letras», La Gaceta Literaria, n 1, 1 de enero de 1927, p. 1.

2. Juan José Morato, «Los redentores del obrero. Pablo Iglesias», La Libertad, 4 de diciembre de 1927 , sin $\mathrm{p}$.

3. José Bernardo San Juan, «Algunas aclaraciones en torno a la revista Vida Nueva (18981900)», Revista Internacional de Historia de la Comunicación, no 3, 2014, p. 1-19.

4. José Luis Cano, "Azorín en Vida Nueva», Cuadernos Hispanoamericanos, no 76, 1968, p. 423-435.

5. Noel Rivas Bravo, «Rubén Darío en la revista Vida Nueva», Philologia hispalensis, vol. 14, $\mathrm{n}^{\mathrm{o}} 1,2000$, p. $249-252$.

6. José Bernardo San Juan, "Ángel Ganivet y la revista Vida Nueva (1898-1900)», Tonos Digital, no 28, enero de 2015.

7. Manuel García Blanco, "Juan Ramón Jiménez y la revista Vida Nueva (1899-1900)», Studia philologica, 1961, p. 31-72. 
luchas entre clericales y anticlericales; es urgente también porque los años de publicación de Vida Nueva fueron de especial virulencia en este campo. Recuérdese, al mismo tiempo, que entre los escenarios de la pugna -cátedras universitarias, congreso de los diputados, etc.- la prensa ocupa un lugar destacado.

Por otro lado el análisis de esta disputa permitirá conocer mejor la figura del montañés. Aunque es una de las personalidades más estudiadas del siglo XIX, el episodio de su enfrentamiento con Vida Nueva -al igual que todo lo relacionado con esta revista -apenas se ha mencionado. Además Menéndez Pelayo ha sido utilizado, en su faceta de intelectual católico, como estandarte de unos contra otros. Decía el escritor de Santander acerca de Cánovas del Castillo que el odium auctoris ${ }^{8}$ había influido mucho en la recepción -unánimemente negativa- de sus obras literarias. Lo que no imaginaría el montañés es que la recepción de su propia obra también se vería alterada por las diversas corrientes ideológicas del siglo XX ${ }^{9}$. La descripción de su lance con los redactores de Vida Nueva permite entrever a un personaje que, al menos en esa ocasión, no era vanguardia de un frente de batalla sino que más bien víctima de ella.

De acuerdo con esos objetivos, el artículo comenzará ofreciendo un retrato de la revista y de cómo fue el anticlericalismo que se daba en ella, se explicará cómo fueron las colaboraciones de Menéndez Pelayo y cómo se dio su «traumática» salida de ella.

\section{LA REVISTA VIDA NUEVA}

Vida Nueva nació el 12 de junio de 1898 -en plenas guerras coloniales- y dejó de imprimirse el 25 de marzo de 1900. En esos 21 meses de andadura aparecieron 8 números de una Edición Popular más los 94 de la publicación original. Era un semanario que había surgido con la vocación de unirse a un grupo floreciente de «revistas nuevas» -prensa de inspiración regeneracionista e impulsada, en su mayor parte, por las jóvenes élites- para brindar soluciones de carácter político y cultural a la crisis española. Se trataba de cabeceras de naturaleza socialista y republicana. Formaban parte del conjunto publicaciones muy conocidas como Revista Nueva (1899), Alma Española (1903-1904), el semanario Germinal (1897-1903, con varias interrupciones), Helios (19031904), Renacimiento (1907), El Nuevo Mercurio (1907), Els Quatre Gats (1899) y Pèl \& Ploma (1899-1903), entre otras.

Desde el punto de vista político tuvo gran relevancia: The New York Herald Tribune celebró su aparición y el New York Times la citaba como su fuente informativa a la hora de entender qué sucedía en Espańa. Promovió en forma

8. Marcelino Menéndez Pelayo, Estudios sobre el teatro de Lope de Vega. Crónicas y leyendas dramáticas de España. Santander, Ed. Nacional, 1949, p. 417.

9. Cfr. Marta Campomar Fornieles, "Cuarenta años de menendezpelayismo», Espacio, Tiempo y Forma, t. 7, 1994, p. 657-683. 
eminente -y consiguió- la revisión del proceso de Montjuich. Su importancia en lo literario no fue menor: según Rubén Darío era «de lo mejor que se publica en Madrid ${ }^{10}$ y los poemas de Juan Ramón Jiménez aparecidos en ella fueron los que llevaron al nicaragüense a enviarle una postal en la que le invitaba a viajar a Madrid para "luchar por el modernismo» ${ }^{11}$. El poeta de Moguer escribió para ella sus primeras críticas literarias y, de hecho, fue la publicación en la que se dio a conocer. A Vida Nueva envió Ángel Ganivet sus últimas colaboraciones horas antes de suicidarse y allí aparecieron cuentos de Blasco Ibáñez y alguna de las primeras críticas de Manuel Machado. La nómina de colaboradores fue notable: Ramiro de Maeztu, Benito Pérez Galdós, Juan Valera, Ramón de Campoamor, Pablo Iglesias, Francisco Villaespesa, Julio Pellicer, Manuel Bueno, Luis Bonafoux, Gregorio Martínez Sierra, Timoteo Orbe, José Echegaray, Leopoldo Alas Clarín e, incluso, Miguel de Unamuno quien publicó allí «Muera D. Quijote», uno de sus artículos más polémicos. De hecho el autor vasco en 1916 todavía guardaba en la memoria las ganas de regeneración propias de esos años en los que Vida Nueva jugó un papel central:

Los que en el 98 saltamos renegando contra la Espańa constituida y poniendo al desnudo las lacerías de la patria, éramos, quien más quien menos, unos ególatras. Pero esa egolatría fue la consecuencia, de cierto hipertrófica, de un descubrimiento moral que hicimos en el fragoroso hundimiento de los ideales históricos españoles [...]. Aquel nuestro movimiento espiritual del 98, aquella recia refriega de pluma, que halló su principal tribuna en Vida Nueva, fue un sacudimiento anárquico y anarquista, fue un ¡sálvese quien pueda! ${ }^{12}$.

Azorín, otro de sus colaboradores, recordaría con añoranza aquellos años de renovación que ya no podrían volver a darse: «Seamos sinceros: ya la decadencia se ha iniciado en los maestros casi viejos, Valle Inclán no volverá a escribir Epitalamio, ni Maeztu sus artículos de Germinal, El País y de Vida Nueva...." ${ }^{13}$.

\section{VIDA NUEVA, PRENSA ANTICLERICAL}

Vida Nueva fue una revista decididamente contraria a la Iglesia católica. La animadversión se manifestaba de muy diferentes maneras. En las siguientes tres notas se sintetizan los elementos más característicos de su anticlericalismo.

10. Noel Rivas Bravo, op. cit., p. 249.

11. Graciela Palau de Nemes, Vida y obra de Juan Ramón Jiménez, Madrid, Biblioteca Románica Hispánica, Ed. Gredos, 1957, p. 125.

12. Miguel de Unamuno, «De las tristezas españolas: Nuestra egolatría de los del 98», Los Lunes de El Imparcial, no 17.583, 31 de enero de 1916, sin p.

13. José Martínez Ruiz, «Pío Baroja y su última novela: Los compañeros», Alma Española, 27 de diciembre de 1903 , p. 9. 


\section{Plurales pero anticlericales}

En los orígenes de la publicación se declaraba la intención de que cupieran todas las ideologías. Era ésta una de sus pretendidas notas definitorias. De hecho su propia estructura organizativa respondía a esta vocación: no había director que pudiera censurar o dirigir la opinión de quienes escribieran en ella. La dirección de la revista la ejercían sus redactores a través de un consejo. En su artículo programático Eusebio Blasco -que fue al principio la cabeza visible de la publicación- manifestaba su voluntad de ser plurales: «cabrán todas las opiniones cultamente expresadas. Cada escuela tendrá su sección, cada clase social la suya ${ }^{14}$. Son múltiples los testimonios de colaboradores en los que se hacía gala de esa libertad. Sin embargo en Vida Nueva habían puesto un pero a su apertura ideológica: «esta publicación será todo lo que se quiera y la quieran llamar, pero no será nunca reaccionaria ${ }^{15}$. Reaccionarios eran cualesquiera que se opusieran al progreso; la Iglesia, según su modo de ver, era esencialmente contraria. "Reaccionario" era un término que se utilizaba prácticamente en exclusiva para designar a los sectores más extremos del catolicismo.

Es cierto que entre los autores se encontraban pensadores de muy diferente condición: había ateos furibundos como José Nakens, clérigos en rebeldía como José Ferrándiz, «socialistas cristianos» como Eusebio Blasco o pensadores como Ángel Ganivet, que, según había dicho en su testamento, no creía en ninguna "religión positiva»" A la vez, muchos de ellos se consideraban verdaderamente religiosos, bien porque eran discípulos de un primigenio y original cristianismo, bien porque eran seguidores de una religión de la libertad, de la razón o, incluso, de la belleza.

Antes aún de que hubieran publicado ningún contenido anticlerical, la prensa católica mostró su escepticismo. En La Lectura Dominical se puede leer que:

El nuevo periódico, si hemos de creer lo que dice el programa, cosa que yo no aconsejaré a nadie, quiere ser 'un periódico para el público, sin compromisos con ningún partido, sin espiritu de escuela determinada (esto regularmente no será verdad); una tribuna en la que quepan todas las ideas y todas las opiniones (pues esto ya es escuela, aunque laica); un periódico en que cada uno de sus redactores podrá opinar y escribir como le parezca'. [...] No crean ustedes que esta es una suposición gratuita [...]. En el periódico Vida Nueva se podrá defender todo menos la ley de Dios y los derechos de la Iglesia ${ }^{17}$.

Obsérvese que en esta crítica se apunta a otra de las claves de la incompatibilidad entre ambos medios; la pretensión de que tengan cabida

14. Eusebio Blasco, «Vida Nueva», Vida Nueva, no 1, 12 de junio de 1898, sin p.

15. Sin firma, Programa inicial: sin título, Vida Nueva, no 1, 12 de junio de 1898, sin p.

16. Ángel Ganivet, Obras Completas, Fernando García Lara, ed., tomo X, Granada, Ed. Diputación de Granada, 2008, p. 1262,

17. Miguel, seud., "Sección de polémica», La Lectura Dominical, n 233, 19 de junio de 1898 , p. 397. 
todas las opiniones ya es, en sí, algo incompatible con cierta manera de entender el catolicismo: para el autor de La Lectura Dominical el error -«una opinión más», desde la perspectiva de Vida Nueva- no debía ser tolerado, es más, debía ser perseguido hasta el punto de prohibirlo.

\section{No a la Iglesia}

A pesar de las muy diferentes posturas manifestadas en Vida Nueva con respecto a la religión, es posible encontrar un común denominador de lo anticlerical cuyo núcleo era el convencimiento de que la Iglesia no era una institución divina sino humana, construida sobre los objetivos de perpetuarse en el poder y de seguir aumentando su riqueza. Para mantenerse arriba se había convertido en una defensora del statu quo y a ello dedicaba sus fuerzas. La moral y los sacramentos (la confesión y el matrimonio, sobre todo) serían formas de control de la sociedad, por más que los propios eclesiásticos no respetaran ni uno ni otro. Los siguientes puntos ofrecen un desarrollo de este pensamiento:

a) La Iglesia busca acaparar riqueza y poder político. Se indignaban por el valor de las propiedades que tenían titularidad eclesiástica, por el dinero que percibían los clérigos y por el trato de favor que el Estado les dispensaba. Publicaron tablas con los inmuebles de la Iglesia. Por el contrario alababan a aquellos clérigos que eran verdaderamente pobres. Eusebio Blasco, por ejemplo, escribió a favor del obispo de Segorbe ${ }^{18}$ a quien no se le habían caído los anillos a la hora de viajar en tercera clase, portar él mismo su maleta en un trayecto de tren y aguantar las palabras soeces de un grupo de obreros.

b) Desde el ámbito religioso se había impuesto una moral -especialmente la sexual- que estaba formulada para controlar a los feligreses, por más que los propios eclesiásticos no la respetaran. Con frecuencia ponían en tela de juicio la integridad de los hombres de Iglesia y denunciaban su impunidad. Por otro lado aquellos que sí vivían honradamente eran considerados unos «engañados» por el sistema y unos reprimidos. Estos temas se solían tratar en clave soez; el poema "Los sobrinos del cura» ${ }^{19}$ es un buen botón de muestra:

\footnotetext{
Que ya sé lo que hace tiempo

la malicia sospechaba:

y es que en este, como en otros

muchos lugares de España,

son los sobrinos del cura

hijos del cura y del ama.
}

18. Eusebio Blasco, «Al Sr. Obispo de Segorbe», Vida Nueva, no 12, 28 de agosto de 1898, $\sin \mathrm{p}$.

19. Venancio Sastre de Olmedo, «Los sobrinos del cura», Vida Nueva, no 62, 13 de agosto de 1899 , sin p. 
Otro texto especialmente duro fue el que dedicó José Nakens a un sacerdote que había decidido colgar la sotana para casarse: «Venga esa mano, clérigo que acabas de abjurar del catolicismo para unirte a la mujer que amas. Eres un hombre, y un hombre honrado. [...] Dirán que el instinto carnal te ha empujado. Error o falsedad. Para satisfacerlo cumplida e impunemente, ningún estado como el que abandonas. Ellos lo saben, y nosotros también ${ }^{20}$.

c) Una forma paradigmática de dominio social se lograba por medio del control sobre las conciencias. A través de la confesión los clérigos fiscalizaban las acciones de los católicos, les imponían penitencias, los conducían de un lugar a otro y les amenazaban con la condenación. Frecuentemente se seńalaba a los jesuitas como los mayores expertos en esta clase de artes. Dionisio Pérez publicó un folletín por entregas titulado Jesús, memorias de un jesuita novicio en donde un novicio explicaba cómo había ido entregando toda su intimidad a sus directores espirituales y cómo estos habían «canibalizado» su personalidad:

Toda mi infancia, sin amor, sin alegrías, en tropel de recuerdos dolorosos, desfila en mi memoria y en mi corazón al escribir este libro. Contemplo tantos días dedicados al exterminio de mi voluntad naciente, [...], al adormecimiento de todos los afectos terrenales, al aprendizaje del disimulo como norma de conducta... ¡y lloro! [...] Pero luego, mirando a mi madre, gozosa de verme, pensé que era ella, ella misma crédula o necia, quien me habla envilecido, entregándome a los que pasaron por mi corazón, como la ventisca de invierno por los campos fecundos, no dejando ni una brizna ni una flor ${ }^{21}$.

d) La Iglesia es, de suyo, anti-regeneracionista. En las páginas de esta revista se sostenía que la Iglesia era enemiga de cualquier progreso por dos razones. Por un lado porque no admitía que nadie pensara de forma distinta a como ellos lo hacían: bajo su imperio era imposible la convivencia de lo diverso. Procurarán mostrar cómo aquellos que habían opinado de forma distinta habían sido aplastados o ninguneados por esta institución. Por otro lado la Iglesia sería antiregeneracionista porque era enemiga de cualquier cambio social. Si los sectores más radicales eran carlistas se debía a que ése sería el único régimen que respetaría completamente la «buena doctrina». Aunque esta cabecera en sus comienzos no exponía a las claras tal idea, conforme fue haciéndose más explícita su lucha perdió el miedo a hacerlo: «Vida Nueva será anticlerical a pesar de ser esto cursi, porque cree sinceramente que en Espańa no se puede ser ni demócrata, ni liberal, ni republicano, ni patriota sin ser enemigo del monaquismo, de la enseñanza religiosa y de la política nea ${ }^{22}$.

20. José Nakens, «Ley de vida», Vida Nueva, no 65, 3 de septiembre de 1899, sin p.

21. Dionisio Pérez, "Jesús. Memorias de un jesuita novicio», Vida Nueva, no 7, 24 de julio de 1898 , sin p.

22. Sin firma, «Vida Nueva ante Silvela», Vida Nueva, no 41, 19 de marzo de 1899, sin p. 


\section{Los estilos del anticlericalismo}

Se pueden diferenciar dos tipologías de artículos de acuerdo con el planteamiento de la crítica. En primer lugar estaban los que buscaban argumentar. Eran artículos pretendidamente científicos y algunos de ellos lograron crear polémica de altura, con réplicas y contrarréplicas. Marcelino Gómez Hurtado, un canónigo lateranense, escribió un artículo ${ }^{23}$ sobre la relación entre la Iglesia y el Estado en el que defendía que una y otro debían de caminar por lados distintos. Artículos argumentativos fueron solo una minoría de los textos anticlericales, pero en la medida en que Vida Nueva fue una revista importante, influyeron mucho. Fernando de los Ríos Urruti confesaba a Unamuno en 1910 (nótese que la revista había desaparecido hacía diez años), el papel relevante que ésta había tenido en la pérdida de su fe: «Hace mucho que su espíritu conoce el mío. Fue uno de los factores más potentes en el influjo que sufrió cuando teniendo dieciséis o diecisiete años tropezó con Vida Nueva y con una crisis sentimental que le separaba del catolicismo y le repelía de la comunión con esa inmensa masa que forma el vulgo culto» ${ }^{24}$.

Sin embargo, en la mayoría de las ocasiones los textos anticlericales eran textos en los que sencillamente se criticaba por medio del insulto o de la ironía. Blasco Ibánez escribió "La lepra frailuna» ${ }^{25}$ en donde acusaba a los religiosos de haber sido la causa de la pérdida de Filipinas:

Lamentamos con toda el alma la situación de nuestros soldados en Filipinas [...]. Pero si al final de tanto heroísmo hemos de perder Filipinas, hacemos votos porque no quede con vida ninguno de los causantes de la catástrofe, y ojalá los campilanes de los insurrectos, ejecutores de una suprema justicia, como en otro tiempo lo fueron las espadas de los bárbaros, se emboten y se mellen a fuerza de afeitar en seco monásticos testuces. Que ninguno vuelva a España. Que sus huesos blanqueen aquella tierra que ha sido para ellos comedor bien provisto y harem de interminables delicias.

\section{LA RESPUESTA ECLESIÁSTICA}

Con un panorama como el descrito no es de extrañar que las fricciones con el poder eclesiástico saltaran a las primeras de cambio. De hecho, buena parte de las causas que acabaron por cerrar esta publicación tuvieron que ver con cierta «resistencia conservadora» muy relacionada con el carácter religioso. El boicot, como se denunció desde la revista, tuvo muchas formas: un obispo declaraba que era una publicación pecaminosa, otro obispo le secundaba, desde los púlpitos se lanzaban invectivas contra ella, los voceros comenzaban a

23. Marcelino Gómez Hurtado, «El reino de Cristo», Vida Nueva, nº 7, 21 de julio de 1898, $\sin \mathrm{p}$.

24. Cit. María Dolores Gómez Molleda, Socialismo español y los intelectuales: cartas de líderes del movimiento obrero a Miguel de Unamuno, Salamanca, ed. Univ. de Salamanca, 1980, p. 510.

25. Vicente Blasco Ibáńez, «La lepra frailuna», Vida Nueva, no 4, 3 de julio de 1898, sin p. 
no publicitarla, ciertos anunciantes empezaron a dudar de la conveniencia de salir en esas páginas, algunos distribuidores desistieron de pedirla y así, poco a poco, acabó ahogándose.

Las acciones promovidas fueron múltiples. Tantas que exceden el límite y el propósito de estas páginas. Un botón de muestra de la respuesta clerical pueden ser las diferentes prohibiciones que los obispos hicieron de ella. La primera llegó a los dos meses de haber salido. En el número 10 se reprodujo una carta en la que el cardenal Spínola, arzobispo de Sevilla, aconsejaba a los fieles de su diócesis que no leyeran Vida Nueva. Junto con la carta apareció la respuesta de Eusebio Blasco ${ }^{26}$. En ese mismo número, como en un añadido de última hora, se recogía la noticia "Otro Obispo»" cuyo contenido, también firmado por Blasco, era igualmente significativo:

También el de Tarragona ha tenido la bondad, que le agradecemos mucho, de prohibir la lectura de Vida Nueva a sus diocesanos. Parece mentira que hombres avezados al confesionario y que empezaron su carrera conociendo el interior de las conciencias, no hayan aprendido que aquello que se prohíbe es lo que más se desea. Esto es esencialmente humano. ¿¿Es una campaña eclesiástica contra Vida Nueva la que comienza? [...] Quédense en su rincón los ignorantes o los espíritus esclavos de lo que manda el Boletín eclesiástico de cada provincia. Para que Vida Nueva viva, le bastan el apoyo y la cooperación de los espíritus independientes, y todavía hay en España más de los que parece.

No faltaron, desde este momento, las referencias en clave de sorna a estos sucesos: Jurado de la Parra, otro colaborador frecuente de la revista, dedicó un soneto jocoso al obispo de Cartagena, tercer obispo que hablaba contra esta publicación ${ }^{28}$. Pero la lista de condenas, si se repasa la prensa de esos ańos, es unánime; en La Correspondencia de España: «El prelado de Badajoz, a semejanza de lo hecho por otros, ha prohibido a los fieles de su diócesis la lectura y circulación del semanario Vida Nueva» ${ }^{29}$; en El Siglo Futuro: «El excelentísimo e ilustrísimo señor Obispo de Menorca ha prohibido a sus diocesanos la lectura del semanario Vida Nueva»" en La Lectura Dominical: «El Boletín Eclesiástico de Santander publica la circular del Sr. Arzobispo de Sevilla, precedida del siguiente preámbulo: por si aún se repartiesen por nuestra diócesis números de la reciente publicación periódica Vida Nueva, nuestro Excelentísimo Prelado recomienda, con todo interés, como si fuese dictada por él, la lectura de dicha circular $»^{31}$.

26. Card. Marcelo Spínola y Eusebio Blasco, "Al Señor Arzobispo de Sevilla», Vida Nueva, $\mathrm{n}^{\mathrm{o}} 10,14$ de agosto de 1898 , sin $\mathrm{p}$.

27. Eusebio Blasco, "Otro Obispo", Vida Nueva, no 10, 14 de agosto de 1898, sin p.

28. José Jurado de la Parra, «Al Sr. Obispo de Cartagena», Vida Nueva, no 12, 28 de agosto de 1898 , sin p.

29. Sin firma, Sin título, La Correspondencia de España, no $14.825,5$ de septiembre de 1898 , $\sin \mathrm{p}$.

30. Sin firma, Sin título, El Siglo Futuro, no 7.100, 6 de septiembre de 1898, sin p.

31. Matraca, seud., "Fuego graneado", La Lectura Dominical, no 245, 11 de septiembre de 1898, p. 594. 
A Sevilla, Tarragona, Cartagena, Badajoz, Menorca y Santander deben sumarse el Obispo de Plasencia ${ }^{32}$, la iniciativa de varios fieles de Salamanca -elevada al Obispo- de prohibirla en la diócesis ${ }^{33}$, las presiones en Astorga para que no se puedan vender "periódicos antijesuíticos»" ${ }^{34}$, la prohibición en Málaga ${ }^{35} \mathrm{y}$ las arengas que desde el púlpito la condenaban en Orense ${ }^{36}$.

\section{MENÉNDEZ PELAYO Y VIDA NUEVA}

\section{Las «colaboraciones» de Menéndez Pelayo en la revista}

La relación de Menéndez Pelayo con la revista fue muy particular. Antes de que naciera los redactores habían enviado cartas a un nutrido grupo de intelectuales -entre los que se encontraba el montañés- a los que les solicitaban colaboraciones. Él no contestó y su silencio fue interpretado como una aprobación tácita a que su nombre figurara, al menos, en la nómina de colaboradores que se publicaba en cada número. Y así salió desde el principio. Lo cual significaba, como mínimo, una provocación para muchos católicos y para la revista suponía una prueba de su "apertura a todos» y una certificación de que un católico "tolerante» podría leerla sin problemas de conciencia.

Aparecieron cuatro artículos con su firma. Ninguno había sido escrito ex profeso, circunstancia que, además, no se avisaba en tres de ellos. Se trataba de textos extraídos de alguna de sus obras y que se incluían sin permiso directo de su autor. Era ésta una práctica habitual en muchos periódicos de la época. Solían rescatarse esas líneas por su relación con algún elemento de la actualidad o para publicitar libros que acaban de ser impresos.

El primero de los artículos, "Guimerá y Cánovas»" formaba parte del prólogo de uno de los volúmenes a las Obras de Lope de Vega. Allí Menéndez Pelayo analizaba obras que tuvieran el mismo argumento que La campana de Aragón. Desde Vida Nueva seleccionaron la parte que alababa la versión de Cánovas del Castillo. El artículo se publicó unos días antes del primer aniversario del asesinato del político y debió de sorprender mucho al lector por tratarse de un escrito elogioso de un conservador sobre un político que también lo era y que aparecía junto a uno de José Nakens, situado en las antípodas ideológicas de ambos.

32. Sin firma, «Voz de apóstol», El Siglo Futuro, no 7.120, 26 de septiembre de 1898, sin p.

33. Sin firma, «Bien por los católicos salmantinos!», El Siglo Futuro, no 7.294, 19 de abril de 1899 , sin $\mathrm{p}$.

34. Sin firma, "Calumnia de neos», El País, no 4.427, 23 de agosto de 1899, sin p.

35. Sin firma, "Una palabra más sobre la prensa periódica», El Siglo Futuro, n 7.123, 29 de septiembre de 1898 , sin p.

36. Sin firma, «La paga del diablo», El Motín, no 46, 23 de diciembre de 1899, sin p.

37. Marcelino Menéndez Pelayo, «Guimerá y Cánovas», Vida Nueva, no 4, 3 de julio de 1898 , sin p. 
«A Jerusalem ${ }^{38}$, el siguiente artículo, fue publicado con motivo del viaje del Emperador Guillermo a Tierra Santa. En la revista afirman que es un texto inédito en el que se muestran las condiciones de los viajes a esa región en el siglo XV. Lo habían tomado del volumen VII de la Antología de Poetas Líricos Castellanos que en esas fechas acababa de salir de la imprenta ${ }^{39}$; el artículo narraba el viaje que Juan del Encina había hecho a Jerusalén en torno a 1519 (en el siglo XVI, por tanto). El texto, en esta ocasión, no incluía referencias anticlericales.

El tercero se titulaba «Los Episodios Nacionales»" ${ }^{40}$ y era una parte del discurso que el escritor de Santander había leído para la recepción de Galdós en la Academia; en él se destacaban los méritos del canario. Vida Nueva era una revista decididamente defensora de lo galdosiano. Éste era un autor muy criticado desde el flanco conservador y el hecho de que Menéndez Pelayo fuera amigo suyo y lo ensalzara, llamaba la atención.

Por último se publicó «Poesía Sacro-Amatoria» ${ }^{41}$ el 1 de enero de 1899 (seis meses después de su primer artículo y siete meses después de que su nombre figurara como colaborador). Estaba extraído del mismo volumen de donde habían tomado «A Jerusalem». En esta ocasión era, en realidad, una reunión de párrafos que alguien extractó de las veinte páginas del original, texto cuyo sentido difería sustancialmente en las dos versiones. Para la revista los aspectos eróticos y escandalosos de la vida de Juan del Encina y así pretendían ofrecer la «verdadera historia» de la Iglesia: comenzaba, por ejemplo, con la descripción de unas cenas/orgías aristocráticas que se organizaban en Roma a las que acudían cardenales, altos representantes de la curia, nobles, prostitutas y actrices. En el original, sin embargo, Menéndez Pelayo trataba de mostrar lo que había dejado escrito en el prólogo de otra de sus obras: «Sinteticemos en concisa fórmula el pensamiento capital de esta obra: el genio español es eminentemente católico: la heterodoxia es entre nosotros accidente y ráfaga pasajera $»^{42}$.

\section{La reacción de Menéndez Pelayo}

El autor de Santander se sintió molesto por la inclusión de «Poesía SacroAmatoria» y escribió una carta a Eusebio Blasco. En ella denunciaba la tergiversación y solicitaba que no volvieran a publicar más textos suyos:

38. Marcelino Menéndez Pelayo, «A Jerusalem», Vida Nueva, no 23, 13 de noviembre de 1898 , sin p.

39. Marcelino Menéndez Pelayo, Antología de Poetas Liricos Castellanos, vol. VII, Madrid, ed. Librería Hernando, 1899, p. 17-21.

40. Marcelino Menéndez Pelayo, «Los Episodios Nacionales», Vida Nueva, no 24, 20 de noviembre de 1898 , sin p.

41. Marcelino Menéndez Pelayo, «Poesía Sacro-Amatoria», Vida Nueva, n 30, 1 de enero de 1899 , sin p.

42. Marcelino Menéndez Pelayo, Historia de los heterodoxos españoles, vol. 1, Madrid, CSIC, 1992 , p. 62. 
Mi estimado amigo: [...] me ha molestado la inserción que en el número 1 de este año ha hecho de unos párrafos de un estudio mío, sin advertir de dónde los tomaba y poniéndoles un título sobremanera impropio. Esos párrafos que en el libro en que están nada tienen de particular porque vienen traídos por la materia histórica de que se trata, resultan escandalosos y malsonantes publicados como artículo suelto [...]. Yo no puedo tolerar que mis escritos sean mutilados de esta manera, ni que se los haga servir para fines enteramente opuestos á mis ideas [...] ¡Cualquiera podrá pensar que yo he escrito ad hoc esos párrafos para Vida Nueva asociándome a compañeros anticlericales que, entre otras cosas, me parecen anticuados y de mal gusto! ${ }^{43}$

En principio la cosa debía quedarse ahí, pero Blasco ya no estaba en Vida Nueva sino que era redactor jefe de El Nacional y vio la oportunidad de ganar lectores para su periódico divulgándola en él. A partir de este instante se pueden distinguir dos planos: la información respetuosa y admirativa transmitida en la correspondencia privada y, por otro lado, los ataques en los periódicos. En cuanto la carta se publicó, Rodrigo Soriano -uno de los redactores más activos de Vida Nueva- se apresuró a escribir ${ }^{44}$ a Menéndez Pelayo para explicarle cómo deploraba que se hubiera dado publicidad a un problema que no debía tenerla y se defendía de las quejas del montañés aduciendo que todo lo publicado en la revista había aparecido como homenaje hacia su obra.

Un día después Blasco escribió a Menéndez Pelayo para darle razón de su comportamiento. Para él no había duda: la publicitación de su carta servía para limpiar su imagen de católico y para evitar que en el futuro se aprovecharan de nuevo de su nombre. En el tono de la respuesta se advierte un distanciamiento de Blasco con respecto a sus amigos de Vida Nueva:

Muy respetable amigo: Así que recibí su carta me apresuré sin perder momento a publicarla en el Nacional del que soy redactor-jefe desde $1^{\circ}$ de año, porque de este modo gano la acción y me adelanto a todo lo que pudieran evitar o desfigurar los que son rectificados. Y en seguida la envié a Vida Nueva pero ya el gran público sabe lo que V. desea que sepa. El Globo la ha reproducido esta mañana y otros periódicos lo harán esta noche. Mándeme como quiera, ya sabe que donde yo esté estoy incondicionalmente a sus órdenes ${ }^{45}$.

El 15 de enero salió el primer número de Vida Nueva tras la publicación de la carta. Volvieron a reproducirla y la contestaron en un artículo ${ }^{46} \sin$ firmar. En él se decía que el montañés había escrito obras verdaderamente libres y otras en las que su libertad se subyugaba al dogma: desde la redacción de la revista pensaban que ese autor por fin se había liberado de su condición de «neo» pero estaban equivocados. Se trataba de una réplica muy dura. Junto

43. Marcelino Menéndez Pelayo, "Una carta», El Nacional, 9 de enero de 1899, sin p.

44. Marcelino Menéndez Pelayo, Epistolario, vol. 15, carta no 108 de 9 de enero de 1899, Manuel Revuelta Sañudo, ed., Madrid, FUE, 1987.

45. Marcelino Menéndez Pelayo, Epistolario, vol. 15, carta no 110 de 10 de enero de 1899 , Manuel Revuelta Sańudo, ed., Madrid, FUE, 1987.

46. Sin firma, «Menéndez Pelayo y Vida Nueva», Vida Nueva, no 32, 15 de enero de 1899, $\sin \mathrm{p}$. 
a ella apareció el artículo "Careo» ${ }^{47}$ en el que se recordaban los párrafos más escandalosos de «Poesía sacro-amatoria». Además, Nakens, atento a todas las rencillas que «olieran» a anticatolicismo, publicó en ese mismo número el artículo "Menéndez Pelayo» ${ }^{48}$ donde alababa la sagacidad periodística de Blasco porque al divulgar la carta había mostrado el verdadero talante del autor de Santander: Menéndez Pelayo no la había escrito por su catolicismo sino por su orgullo herido, lo cual se inferiría del hecho de que «desde que leyó la lista de redactores de Vida Nueva y vio en ellas ciertos nombres, especialmente el mío, debió negarse a que el suyo figurase en la de colaboradores».

Soriano envió otro mensaje $e^{49}$ a Menéndez Pelayo en donde declaraba ser el autor del texto anónimo de Vida Nueva y en el que -sorprendentemente para quien lo ha leído- dice sentir admiración hacia él: al escribirlo consiguió que no lo hubiera hecho otro en un tono más hiriente. Vuelve a sostener que todo hubiera quedado en agua de borrajas si Blasco no hubiera decidido publicitar la carta, le pide disculpas y le reitera su deseo de amistad. Esa carta llegó a la vez que otra de Jacinto Octavio Picón, buen amigo de Menéndez Pelayo y colaborador de Vida Nueva. En el ámbito íntimo, al igual que Soriano, todos le muestran apoyo y comprensión. Picón, además, estaba en deuda con él por las gestiones que desde Santander se habían hecho para que pudiera acceder a la Academia ${ }^{50}$. Decía Picón:

Mi muy querido amigo: sabiendo V. como sabe el cariño que le profeso, independiente en absoluto de la gratitud que le debo por lo que recientemente ha hecho conmigo, comprenderá lo que habré sentido cuanto ha pasado a consecuencia de la carta publicada en El Nacional. No le he escrito a V. antes porque me habían dicho que debía V. llegar a Madrid de un momento a otro. En fin, aquí hablaremos: y si alguna duda tiene espero convencerle de que el origen de todo ha sido la inserción de la carta en El Nacional y que en los que dirigen Vida Nueva no hay nadie que no le respete a V. y considere tanto como merece ${ }^{51}$.

Pero la cosa no quedó así: en el número siguiente Blasco contestó con un artículo $^{52}$ a Nakens para aclarar que él no era un ateo sino un cristiano convencido. En ese mismo número se publicaba una nota ${ }^{53}$ en la cual se comunica que Menéndez Pelayo había escrito a otro redactor de la revista -no se decía a quien y no conservamos ese texto- y le mostraba el malestar porque se hubiera publicado su anterior carta (era una carta privada). Vida Nueva «lamenta» lo ocurrido y «cree terminado aquí el asunto».

47. Marcelino Menéndez Pelayo, "Careo», Vida Nueva, no 32, 15 de enero de 1899, sin p.

48. José Nakens, «Menéndez Pelayo», Vida Nueva, número 32, 15 de enero de 1899, sin p.

49. Marcelino Menéndez Pelayo, Epistolario, vol. 15, carta no 121 de enero de 1899, Manuel Revuelta Sañudo, ed., Madrid, FUE, 1987.

50. Jacinto Octavio Picón, «El nuevo director de la Biblioteca Nacional», Vida Nueva, nº 6, 17 de julio de 1898 , sin p.

51. Marcelino Menéndez Pelayo, Epistolario, vol. 15, carta no 123 de 16 de enero de 1899 , Manuel Revuelta Sañudo, ed., Madrid, FUE, 1987.

52. Eusebio Blasco, «A Nakens», Vida Nueva, no 33, 22 de enero de 1899, sin p.

53. Sin firma, «Menéndez Pelayo», Vida Nueva, no 33, 22 de enero de 1899, sin p. 
Sin embargo aquellas no fueron las únicas reacciones. Las publicaciones católicas se hicieron eco de la polémica y la interpretaron de dos formas. La mayoría se alegró del «desplante» del crítico de Santander a los anticlericales de Vida Nueva -por ejemplo en La Unión Católica ${ }^{54}$ - o sencillamente ofrecieron la noticia y aprovecharon para criticar a la revista, tal y como hicieron en $\mathrm{La}$ Lectura Dominical ${ }^{55}$. Esta reacción de alegría -y de felicitación por su valentíase observa también en la correspondencia de esas fechas. Recibió dos cartas ${ }^{56}$ de admiradores anónimos alabando su actitud y una tercera, en la misma línea, del arzobispo de Burgos, Gregorio Aguirre ${ }^{57}$.

Pero hubo quienes aprovecharon la ocasión para criticar su tibieza. El texto más severo fue el que apareció en El Siglo Futuro ${ }^{58}$. El comienzo del artículo deja a las claras cómo a pesar de que entienden que Menéndez Pelayo se ha convertido en un católico tibio, deben felicitarle cuando acierta:

Le hemos censurado muchas veces por liberal conservador, después de haberle oído condenar en otro tiempo el liberalismo; le hemos censurado por haber ido a mezclarse con los heterodoxos, después de haberlos fustigado en su obra monumental; le hemos censurado por haber ido a acreditar en su nombre el Ateneo, después de haber dicho de él, en mejores tiempos, que era un blasfemadero público que sólo servía para entontecer, esterilizar y quitar la fe a la juventud; le hemos censurado por dejar que su nombre figurase entre los colaboradores de Vida Nueva. Justo es que cuando una vez protesta, más o menos explícitamente, contra alguno de los pecados de que le acusamos, nos apresuremos a publicar su protesta, y aun a aplaudirla en lo que tiene de plausible.

Y una vez que lo han elogiado, critican duramente las razones por las que ha decidido solicitar que no vuelvan a publicarle:

¿Qué significa el último párrafo de su carta? "Por lo mismo que nadie (que yo sepa) se ha quejado ni escandalizado hasta ahora de dicho artículo, creo que procede de mi parte esta sincera manifestación, que en otro caso quizá no hubiera hecho". Quien se quejó y escandalizó de ver nombres que se tienen por católicos entre los colaboradores de Vida Nueva, al condenarla, fue el señor Arzobispo de Sevilla, fueron los demás Prelados que hicieron suya y confirmaron la condenación. ¿Por eso no procedió entonces, por parte del Sr. Menéndez Pelayo, a retirar su nombre de Vida Nueva? ¿Quizá por eso no lo retiró? ¿Por no ceder a las quejas y condenaciones de los Obispos? ¿Procedía esperar a que nadie pudiese creer que el Sr. Menéndez Pelayo cedía a las quejas y censuras de los Prelados? ¿Era preciso que Vida Nueva llegase hasta truncarle los párrafos de sus escritos y ponerles títulos caprichosos para que el Sr. Menéndez

54. Sin firma, "Menéndez Pelayo y Vida Nueva», La Unión Católica, no 3.461, 11 de enero de 1899 , p. 1.

55. Minimus, seud., "Sección de polémica», La Lectura Dominical, n 264, 22 de enero de 1899 , p. 55.

56. Marcelino Menéndez Pelayo, Epistolario, vol. 15, carta no 117 de 14 de enero de 1899 y carta no 145 de 14 de febrero de 1899, Manuel Revuelta Sañudo, ed., Madrid, FUE, 1987.

57. Marcelino Menéndez Pelayo, Epistolario, vol. 15, carta no 136 de 1 febrero 1899, Manuel Revuelta Sañudo, ed., Madrid, FUE, 1987.

58. Sin firma, "Vida Nueva y Menéndez Pelayo», El Siglo Futuro, n 7.211, 10 de enero de 1899, p. 1. 
Pelayo se enfadase de andar entre "compañeros anticlericales que, entre otras cosas, le parecerán anticuados y de mal gusto", pero que sobre todas las cosas, para un cristiano, son grandísimos herejes, apóstatas y enemigos declarados de Jesucristo y de su Iglesia?

\section{Conclusiones: Un AUTOR EN MitAd DEL FUeGo}

Tras haber mostrado cómo era Vida Nueva, cómo fueron los artículos que el montañés publicó en ella y cómo se había producido su salida se pueden extraer varias conclusiones acerca de su postura en este conflicto. Estas conclusiones se exponen en varios puntos:

a) Vida Nueva era una revista abiertamente anticlerical.

b) Menéndez Pelayo conocía esa revista, sabía que se estaba incluyendo su nombre en ella y conocía el tenor de sus textos anticlericales. Lo sabía porque había recibido notificaciones diferentes en las que se mencionaban estas cuestiones. Eusebio Blasco le escribió una carta ${ }^{59}$ el 8 de junio (recuérdese que Vida Nueva nació el 12) con un membrete de la revista para solicitarle indulgencia por un error que había cometido en un artículo de El Liberal ${ }^{60}$ (había confundido Rioja con Argensola). Y le escribió también Picón en julio de ese año ${ }^{61}$ con el membrete de la revista. Blasco volvió a escribirle otra carta ${ }^{62}$, en julio, para decirle que la había dejado porque «no se puede chocar de modo tan brutal con ciertas personas y cosas, ¿verdad?» en referencia muy posiblemente a la furia anticlerical del texto «La lepra frailuna» de Blasco Ibáńez, texto que ya ha sido comentado.

Por último, en septiembre de ese año, recibe el mensaje de un clérigo, amigo de la familia, en el que le insta a que retire su nombre de la lista de colaboradores de esa publicación. El tono es cariñoso pero no deja lugar a las dudas:

Queridísimo señor y paisano mío: las íntimas relaciones que me unen con sus Padres y Hermana Religiosa y por consiguiente con V., el grande aprecio que V. ha merecido ante el mundo entero, y el ser sana gloria sin segunda de nuestro país natal; además, los fueros de la verdad y de nuestra sagrada Religión me instan vivamente hace tiempo para escribirle y rogarle con todo interés que retire su nombre de entre los escritores de esa infame, impía, falsaria, pestilencia (sic) y condenada publicación "La vida nueva”. Creo he dicho bastante. V. no fue nunca de esos, y antes morir que hacer causa común con ellos. Conste pues, que visto lo visto retira su nombre y detesta tales infamias. Ya me conoce: el amor de V. y de su buen nombre, de sus glorias y eterna felicidad son los móviles de quien más le ama ${ }^{63}$.

59. Marcelino Menéndez Pelayo, Epistolario, vol. 22, carta no 283 de 8 de junio de 1898, Manuel Revuelta Sañudo, ed., Madrid, FUE, 1987.

60. Eusebio Blasco, «Crónicas», El Liberal, n 6.823, 8 de junio de 1898, sin p.

61. Marcelino Menéndez Pelayo, Epistolario, vol. 14, carta no 620 de 4 de julio de 1898, Manuel Revuelta Sañudo, ed., Madrid, FUE, 1987.

62. Marcelino Menéndez Pelayo, Epistolario, vol. 14, carta no 681 de 12 de julio de 1898, Manuel Revuelta Sañudo, ed., Madrid, FUE, 1987.

63. Marcelino Menéndez Pelayo, Epistolario, vol. 22, carta no 754 de 7 de septiembre de 1898, Manuel Revuelta Sañudo, ed., Madrid, FUE, 1987. 
c) A pesar de que conocía esto el santanderino no hizo nada. El integrismo católico y el anticlericalismo más radical tenían en común una visión excluyente de la realidad: desde su perspectiva aquellos que no estaban con ellos, estaban contra ellos.

Menéndez Pelayo no compartía esa forma de ver las cosas. Sólo hizo algo cuando tergiversaron sus textos. No le daba importancia a aparecer en esa revista, siempre y cuando pudiera expresarse libremente. Obsérvese que en la carta de protesta no se enfada por aparecer en la lista de colaboradores sino porque hubieran cambiado el sentido de sus palabras. Frente a esta actitud, clericales y anticlericales coinciden en sus críticas: Menéndez Pelayo debía de haber salido de la publicación al ver el nombre de Nakens junto al suyo.

d) Menéndez Pelayo se ve envuelto en la refriega sin haber hecho nada. Y esto da una muestra del tenor de los enfrentamientos en esos años así como de cierta postura neutral que, al menos en esta ocasión, mostró. 